\title{
Theoretical models of time-space: the role of transport networks in the shrinking and shrivelling of geographical space
}

\author{
Alain L'Hostis, Université Paris-Est, LVMT, Inrets
}

\section{Keywords}

Contraction, time-space convergence, time-space, cartography, shrinking, shrivelling, theoretical models

\section{Abstract}

Understanding distances between places is a fundamental task for the geographer, while the representation of distances constitutes one of the major functions of cartography. This is why time-distance representation constitutes a key tool for the contemporary geographer. The purpose of this chapter is, in a first step, to expose a set of solutions to the cartographical representations of distances as transformed by transport means. In a second step we will discuss the relations between these cartographical solutions and the theoretical geographical discourse on time-space structured around classical theoretical models.

\section{Introduction}

Understanding distances between places is a fundamental task for the geographer, while the representation of distances constitutes one of the major functions of cartography. This is why time-distance representation constitutes a key tool for the contemporary geographer.

Among the types of maps introduced to represent time-space anamorphoses were supplemented with time-space relief cartography in the 1990s.

On the one hand the present globalisation process has only been made possible through a reduction in time-distances allowed by high speeds, and particularly through the development of air transport. On the other hand the metropolitanization process seen as the urban counterpart of globalisation is deeply associated with the development of air platforms. Both phenomena are intrinsically linked to the formation of distances, and especially timedistances.

The purpose of this chapter is, in a first step, to expose a set of solutions to the cartographical representations of distances as transformed by transport means. In a second step we will discuss the relations between these cartographical solutions and the theoretical geographical discourse on time-space structured around classical theoretical models.

\section{Transport networks produce distances: a cartographic problem}

To understand the present global space it is necessary to underline the major role played by high speeds in the structuring of metropolitan spaces. These high speeds have allowed the development of communications on a global scale. But, in the mean time, high speeds operate a dramatic selection of places.

While this movement highlights the high places of global communication, the secondary networks and spaces remain present in the interstices. A key point in the formation of global 
time-distances is the fact that these secondary networks are disqualified when compared to the main high-speed networks.

In view of these phenomena the recent literature insists on the differentiation of space where global functions can be located in the close spatial neighbourhood of spaces of dereliction and exclusion (Graham and Marvin 2001) and on inequalities in space favouring largest centres (Knowles 2006).

\section{Figure 1 : the phenomenon of spatial inversion}

But how to represent this complicated set of networks and relations in space? To tackle this question means considering the broader perspective of the representation of distances. In this field Bunge has stated that basically two ways are available either "representing complicated distances on simple maps, or representing simple distances on complicated maps" (Bunge 1962)

In his classical example of the complicated relations in space generated by contemporary transport means, Bunge considers the movements from intermediary space to higher level cities with a trip from somewhere in Montana to the metropolis of Chicago. The articulation of transport modes, here cars and planes, implies in this example that the shortest path in time space takes a completely different shape beyond and after a particular point of indifference. Leaving from Butte would mean driving directly to Chicago, while starting from somewhere closer to the Pacific coast involves a trip by car to Seattle followed by a flight. This phenomenon of spatial inversion that follows an intuitive logic from a transport perspective provokes a disturbance in the order of proximities. If we refer to Cauvins's formalism (Cauvin 1984), while the Rocky Mountains are located between Seattle and Chicago in chorotaxic space -the usual geographic space- their position in functional space is different: in the transport space it is Seattle that stands between the Rocky mountains and the Great Lakes. The identification of the phenomenon of spatial inversion constitutes a key justification of the research of new representations of time-space that would render this complicated set of distances. It is a direct call to complicate the map in order to allow the representation of distances that would be simpler to read.

In this perspective, time-space anamorphic cartography is the first proposal in which one moves the locations in order to better respect time-distances. An example is given by Shimizu showing the contraction of Japan due to the development of the high-speed train networks between 1962 and 1992 (Shimizu 1992). In the field of the representation of distances, anamorphosis belongs to the type of cartography defined by Bunge as simpler distances on a complicated map. Two elements of information on time-distances can be read from such a representation: the overall space contraction and the local deformations produced by highspeed lines. If the new transport networks had been characterised by homogeneity and anisotropy the shape of the external borders of the country would have remained unchanged.. Only size would have been reduced. All the distortions from the usual and conventional shape of Japan indicate directions privileged by the shape of the networks. The literature on networks has abundantly expressed the idea that modern transport provokes heterogeneousness in space (Dupuy 1991; Castells 1996; Graham and Marvin 2001; Knowles 2006).

This model, however, is subject to limitations. The major criticism of the application of anamorphosis to the representation of distances is the fact that if two locations, for instance two cities, are getting closer due to a new transport link, this does not mean that the space in between is also gaining in accessibility. Toll motorways are examples of the "tunnel effect" of some infrastructures where the limited access points reduce the accessibility gains to a set of subspaces, and is not distributed evenly along the line (Plassard 1976). This phenomenon is even more pronounced in the case of high-speed rail (Murayama 1994; Mathis 2007) and is 
one of the major characteristics of air transport (Haggett 2001). Furnishing an illustration of this limitation, the phenomenon of spatial inversion cannot be read from the anamorphic map because of the principle of the preservation of the order of proximities which can be found in most methods developed in the literature (Shimizu 1992; Spiekermann and Wegener 1994; Clark 1999; Kotoh 2001).

Displacing the locations on the map is not the only way in which distances can be represented. The idea of drawing the transport lines between places in such a way that different distances are shown was introduced in the 1980's (Plassard and Routhier 1987; Tobler 1997). In the example proposed by Tobler, location of cities and network nodes remains unchanged, as compared to their usual cartographic position. The length of roads between the nodes is displayed in the form of a spring, the intensity of the tension indicating the sinuousness of roads unevenly distributed in this mountainous area in western Colorado. In this model one can obtain the information on the difficulty of linking two places by reading the visual length of the links. The notion of visual length was introduced (L'Hostis 2003) to render account of the capacity of a reader of a map to extract the information on the length of a route from the analysis of the shape of the path. A straight segment can be converted in kilometres through a direct use of the scale, while a sinuous curve will indicate a longer road. This principle is used in the spring map to express the idea of privileged and handicapped directions.

\section{Figure 2 : spring map of roads in western Colorado}

The spring map model can indicate the shortest directions in space. Being a non-Euclidean representation, it displays the idea that the shortest paths often differ from the straight line. In this perspective, it constitutes a possible proposal to the call for non-Euclidean geography (Golledge and Hubert 1982; Müller 1982). More recently, but in the same direction, a model has been formulated to introduce a three dimensional surface that allows the representation of different speeds in urban space (Hyman and Mayhew 2004).

Sharing a principle of construction similar to that of the spring map, the time-space relief map was introduced in the 1990s (Mathis, Polombo et al. 1993; L'Hostis 1996; Mathis 1996). This type of representation preserves the location of places but exploits the resources of the third dimension to draw the various speeds and the corresponding time-distances in a multimodal network.

\section{Air and road modes as major inter- and intra-metropolitan transport systems}

Globalisation, considered together with metropolitanization as its urban counterpart, is being made possible by the development of efficient, long-haul and short-haul transport systems. If metropolises can be defined as urban entities that communicate on a global scale, the air mode constitutes the major passenger transport system associated with globalisation (Sassen 1991; Haggett 2001). Indeed, the equipment of metropolises with airport infrastructure, the number of flights and destinations available or the air distances are often used as indicators of the position of cities in the global competition (Grubesic and Zook 2007). Nevertheless, the development of the air mode during the $20^{\text {th }}$ century and beyond has not lead to the replacement of other slower transport systems. Each transport mode has developed inside its own space of predominance, with fierce competition in the margins. On the scale of metropolitan spaces, the road system can be considered as the major mode, even if regional specificities can be stressed. The overall picture of mobility involves two distinct levels with the agglomeration or local level dominated by car and the longer distance dominated by air. This typology has to be put in correspondence with the functioning of urban systems having intra-metropolitan and inter-metropolitan components associated with privileged transport 
modes. In order to complete the analysis, this picture has to be enriched marginally with the development of other transport systems, urban public transport and high-speed rail, each of them operating as a complement to, rather than in substitution for cars and planes.

Considering simultaneously the high-speed and lower-speed transport modes on a continental scale in as single time-space relief cartography was proposed by L'Hostis (L'Hostis 2009). This representation is here proposed under a different angle of view. When a usual 30 degrees was used, as in almost all previous time-space cartographies (Mathis, Polombo et al. 1993; L'Hostis 1996; Mathis 1996), this map adopts a 45 degrees angle of view. As the differential of speeds of each subspace reaches a ratio of more than 6, this angle allows highlighting the dichotomy of time-spaces, between the top level network high-speed and the banal lower speed non-metropolitanized space.

In the USA, the air and road transport systems create a complicated time-space that the relief cartography helps to better consider.

After having developed the cartography solutions to the problem of distances, we will now expose the theoretical background of this cartography, relating it to one of the most fundamental tasks of the geographer: understanding space and distances.

Figure 3 : High-speed by air versus lower terrestrial speeds: The shrivelling USA

\section{The theoretical models of time-space, from shrinking to shrivelling}

In geography one can find several theoretical models elaborated to understand time-space. These model consider the movements of contraction/shrinking, of convergence, of divergence, and finally of crumpling and shrivelling.

In geography the rhetoric of world contraction can be considered as a fundamental observation with early references of the ancient Greeks that perceived the evolution of vessel techniques at the time-scale of the life of a human being, and linked it to the reducing of distances between places in the Mediterranean sea (Abler, Janelle et al. 1975; Braudel 1979). In the $19^{\text {th }}$ century already maps of now classical French geography depicted the contraction of the national territory with the improvements in terrestrial transport, while German cartographers mapped the improvement in maritime transport on a global scale showing the reduction in travel times between Europe and the rest of the world (Brunet 1987). More recently, in the domain of theoretical geography, Forer has developed the principle of timespace contraction (Forer 1978).

Nevertheless, criticisms of the contraction model has been made noticeably by Kirsch stating that "space is not "shrinking" but must rather be perpetually recast" (Kirsch 1995). According to Kirsch, the evolution of time-space cannot be seen as a simple contraction or shrinking process. Disagreement to the uniform contraction idea can be found in several geographers works on cartographical developments (Boggs 1941; Abler, Janelle et al. 1975; Haggett 1990). More recently Knowles uses the expression of a "shrunken but misshapen world" to describe the present time-space where contraction is all but uniform (Knowles 2006). Indeed, the abandon of commercial supersonic flights, the development of congestion and the increasing concern about security in the air transport system are the cause of contradictory movements of convergence and divergence on time-space.

The notion of time-space convergence was introduced (Janelle 1968; Janelle and Gillespie 2004) to show that larger cities benefited more than smaller cities from the contraction of time-space by faster transport means. For Janelle the modernisation of transport systems is seen as a factor of concentration in urban agglomerations. In history, the increase in transport speeds has benefited larger cities more than smaller settlements. According to Christaller's theory of urban hierarchy, large cities are more dispersed in space than smaller ones. Two neighbouring large cities will then be separated by a much longer distance than any two 
neighbouring smaller cities. Janelle demonstrated that the increase in speed delivers a stronger effect on time-space contraction on long distances than on short distances. The evolution of the system of speeds gives an advantage to the larger cities over smaller ones, a conclusion which is in line with the literature on metropolitanization. The identification of privileged places in the process of space contraction is for Knowles still an idea to be demonstrated in order to challenge misrepresentations of uniform time-space shrinkage (Knowles 2006). More recently the literature on globalisation has taken as its base the principle of fast communication and transport on a global scale (Sassen 1991; Smith and Timberlake 2002; Taylor 2004). Only global transport systems have made the present movement of globalisation and the unprecedented concentration of population in major metropolises possible.

The initial discussion on the three-dimensional model presented here considered the terrestrial relief as the space of reference. The expressions time-space peaks and time-space valleys referred to the relative position of portions of space in the representation. In the time-space deformation following the introduction in the French national space of the high-speed train system (Mathis, Polombo et al. 1993), the development of new high-speed tangential axis was seen as a way to fill up the valleys dug by the introduction of a differential in transport speeds combined with a star shape of the network. These initial contributions emphasized the analogy with the terrestrial relief.

Later, the idea of a time-space 'crumpling' was introduced to develop the metaphor (L'Hostis 2000) on a representation of the European space deformed by the high-speed rail network. The image developed is that of the deformation of a shrivelled sheet of paper, an idea of three dimensional treatment of a plane. The metaphor refers to a shortening of some distances while preserving the initial geographical surface. The metaphor of 'crumpling' opposes the two spaces of high and low speeds and suggests a three dimensional geometric construction coherent with the concept behind the representation. It also proposes a rather negative image with the crumpled surface seen as a degradation of the ideal unaltered flat plane. A positive perspective can be built, considering that the crumpled shape, being more compact than the flat surface, allows for shorter paths between locations. The crumpling metaphor gives an evocative image of the bad treatment reserved for interstitial spaces, but is not as expressive of the global contraction of geographical space with the increase in speed.

It is relevant to associate these reflections on the representation of geographic time-space with some recent developments in theoretical physics: the astrophysicist Luminet describes the shape of the universe as crumpled around the idea of multiple folding due to time-space deformation, according to the theory of general relativity (Luminet 2001). Even if establishing relations between completely different fields invites us to remain cautious (a use of common words is not sufficient to validate a comparison), it is noticeable that both systems of representation are tightly linked to the identification of a maximum speed. Indeed, the light speed is one of the three fundamental constants in physics. Astrophysicists have to compose with the existence of a maximum speed, light-speed on the universal scale, when geographers have to take into account the maximum speed of transport given by the air mode to understand the terrestrial time-space. In order to better understand space, both reflections seem to face the need to build complicated representations that divert radically from common Euclidean geometry.

In a different field, psychoanalysts have been studying the crumpled spaces (Diener 2008) in order to understand the linkages realised in the time-space of dreams, where associations of ideas lead to direct relations between locations that can be very distant in time-space. A crumpled space, defined by reference to the astrophysicist Luminet work as "welded on itself by several points" realise this kind of connections (Diener 2008). The analogy goes there much further: in the geographic space, fast transport systems realise direct connection 
between remote locations, advocating for the development of crumpled time-space cartography, while in the time-space of dreams, direct connections between remote locations constitutes an essential property. The movement of crumpling generates new connections, new proximities that reflect the properties of geographical space and the properties of the time-space of dreams.

In the evolution of the discourse produced on time-space relief, the following step explores a different type of metaphor based on the idea of shrivelling. The first use of the word must be credited to Tobler through his commentary on the L'Hostis-Mathis image, when he stated that "the world is shrivelling as it shrinks" (Tobler 1999). We move here from an image of shaping an inanimate entity, an artefact, crumpling a sheet of paper, to a principle of natural evolution of a living organism, the shrivelling of a fruit. The shrivelling expresses an idea of contraction with deformation of the envelope: the volume decreases while the external envelope keeps its initial surface.

The strength of the metaphor lies in the combination and the linking of two complementary movements of contraction and deformation of the surface. It is the reduction of the volume due to a loss of substance that provokes the deformation of the skin of the fruit. In geographic terms, it is then possible to explain the complicated shape of the map by the global contraction due to high speeds. The model generates forces of contraction along air routes that apply on high-speed nodes, i.e. metropolises. As L'Hostis proposed (L'Hostis 2009), "high speeds and metropolitanization make the world shrivel as it shrinks" would then be a reformulation of Tobler's statement.

\section{A social space in maps: "It took me one hour to get there"}

To conclude this chapter we propose to discuss a social dimension of time-space that can be read from the analysis of time-space relief cartography.

Let's consider the terminal T2 at the Roissy-Charles-de-Gaulle airport near Paris. Several persons present inside the terminal may state "it took me one hour to get there": the airline travellers that came at $600 \mathrm{~km} / \mathrm{h}$, the high-speed-train travellers at an average of $250 \mathrm{~km} / \mathrm{h}$, but also the airport employees that went at work by car through the congested Ile-de-France urban region at $20 \mathrm{~km} / \mathrm{h}$ on average, and also those who came by public transport at $10 \mathrm{~km} / \mathrm{h}$ from the surroundings of the airport. Each of them took an hour to arrive there, but each at a different speed, each with a profoundly differing kinaesthetic experience (Hall 1966). The first persons belong to the global networks; they occupy the Higher Metropolitan Jobs whose concentration is one of the most revealing markers of the metropolitanization (Rozenblat and Cicille 2003). They evolve in the space of horizontal relations between metropolises, the space of globalisation. Their time-space is the top level network-space in the relief cartography.

The second category belong to a multipolarized urban space, made possible by the "HighSpeed Train web" that links the French cities where live the "neighbours of one of the rare global cities" (Viard 2008).

The third category belong to the local networks, the slow networks. Their inhabitants live inside the time-space abysses located around the high-speed nodes. They may pass members of the two other categories, but they don't get access to the high-speeds. Their time-space has a steep slope. They live in the folds of the crumpled time-space. Their time-space is almost orthogonal to that of the metropolitan workers.

The time-space crumpling renders time-distances that coexist, renders the propagation of a movement at differing speeds, with differing transport means. Building a representation of contemporary time-space means building a synthesis of these distinct spaces, of these distinct time-spaces. Such is the purpose of time-space relief cartography. 


\section{Conclusion}

We have exposed in this chapter several models of cartographical representation of the problem of distances produced by transport means, a problem of fundamental interest for the geographer. In this section, anamorphosis, spring maps and then crumpled relief maps are discussed. In a second step we have analysed the relations between these cartographical solutions and the general discourse on time-space in Geography. Complex and sometimes contradictory phenomenon occurs in time-space, and each cartographical model is able to account for parts of these phenomena. Time-space relief cartography brings an image associated with metaphors linking it to the crumpling of sheet of paper and to the shrivelling of a fruit. The discussion leads then to astrophysicist's conceptions and to recent developments in psychoanalysis. Finally it is proposed to consider the social dimension of time-space: time-space relief cartography is then seen as a representation of the encounter between socially distinct spaces in nodal points located inside metropolises.

\section{References}

Abler, R., D. D. Janelle, et al. (1975). Human geography in a shrinking world. North Scituate, Duxbury Press

Abler, R., D. G. Janelle, et al. (1975). Human Geography in a Shrinking World. Scituate, Duxbury press

Boggs, S. W. (1941). "Mapping the changing world: suggested developments in maps." Annals of the Associations of American Geographers 31(2): 119-128.

Braudel, F. (1979). Civilisation matérielle, économie et capitalisme, Le Temps du monde. Paris, Armand Colin.

Brunet, R. (1987). La Carte mode d'emploi. Paris, Fayard/RECLUS.

Bunge, W. (1962). Theoretical geography. Lund, Gleerup.

Castells, M. (1996). The Rise of the Network Society. Oxford, Blackwell.

Cauvin, C. (1984). Espaces cognitifs et transformations cartographiques. Lettres et Sciences Humaines. Strasbourg: 304.

Clark, G. (1999). "Where is Stranraer now? Space-time convergence re-visited." World Transport Policy \& Practice 5(2): 11-17.

Diener, Y. (2008). "Un Espace chiffonné est-il un espace lacanien?" Essaim 2(12): 9-15.

Dupuy, G. (1991). L'Urbanisme des réseaux. Paris, Armand Colin.

Forer, P. (1978). "A Place for plastic space." Progress in human geography 2(2): 230-267.

Golledge, R. G. and L. J. Hubert (1982). "Some comments on non-Euclidean mental maps." Environment and planning A.(14): 107-118.

Graham, S. and S. Marvin (2001). Splintering Urbanism, networked infrastructures, technological mobilities and the urban condition. London, Routledge.

Grubesic, T. and M. Zook (2007). "A ticket to ride: Evolving landscapes of air travel accessibility in the United States." Journal of Transport Geography 15(6).

Haggett, P. (1990). The Geographer's Art. Oxford, Basil Blackwell.

Haggett, P. (2001). Geography, a global synthesis. Harlow, Prentice Hall.

Hall, E. T. (1966). The Hidden dimension. Garden City, New-York, Anchor books.

Hyman, G. M. and L. Mayhew (2004). "Advances in travel geometry and urban modelling." GeoJournal(59): 191-207.

Janelle, D. G. (1968). "Central place development in a time-space framework." Professional geographer(20): 5-10. 
Janelle, D. G. and A. Gillespie (2004). "Space-time constructs for linking information and communication technologies with issues in sustainable transportation." Transport Reviews 24(6): 665-677.

Kirsch, S. (1995). "The Incredible shrinking world? Technology and the production of space." Environment and Planning D: Society and Space 13(5): 529-555.

Knowles, R. D. (2006). "Transport shaping space: differential collapse in time-space." Journal of Transport Geography 14(6): 407.

Kotoh, H. (2001). New ideas of time maps which shows exact times partially or maintain the topological structure. Colloque Européen de Géographie Théorique et Quantitative, Saint-Valéry-en-Caux.

L'Hostis, A. (1996). "Transports et Aménagement du territoire: cartographie par images de synthèse d'une métrique réseau." Mappemonde(3): 37-43.

L'Hostis, A. (2000). Multimodalité et intermodalité dans les transports. Atlas de France: transport et énergie. L. Chapelon, GIP RECLUS/La documentation française. 11: 99112 .

L'Hostis, A. (2003). "De l'espace contracté à l'espace chiffonné. Apports de l'animation à la cartographie en relief des distances-temps modifiées par les réseaux de transport rapides." Revue Internationale de Géomatique 13(1).

L'Hostis, A. (2009). "The shrivelled USA: Representing time-space in the context of metropolitanization and the development high speeds." Journal of Transport Geography.

Luminet, J.-P. (2001). L'Univers chiffonné. Paris, Fayard.

Mathis, P. (1996). La Stratégie des réseaux de transport dans le grand Ouest. L'Entreprise Atlantique. Y. Morvan. Paris, Editions de 1'Aube: 97-111.

Mathis, P. (2007). Graphs and Networks: Multilevel Modelling. London, ISTE.

Mathis, P., N. Polombo, et al. (1993). Les Grandes vitesses. Circuler demain. A. Bonnafous, F. Plassard and B. Vulin. La Tour d'Aigues, DATAR

Editions de 1'Aube: 129-142.

Müller, J.-C. (1982). "Non-Euclidean geographic spaces: mapping functional distances." Geographical analysis 14: 189-203.

Murayama, Y. (1994). "The impact of railways on accessibility in the Japanese urban system." Journal of Transport Geography 2(2): 87.

Plassard, F. (1976). Les Autoroutes et le développement régional. Lyon, Economica/Presses Universitaires de Lyon.

Plassard, H. and J.-L. Routhier (1987). Sémiologie graphique et évaluation. Lyon, A.R.T.U.R.

Rozenblat, C. and P. Cicille (2003). Les Villes européennes, analyse comparative. Paris, La Documentation française/DATAR.

Sassen, S. (1991). The Global City: New York - London - Tokyo. Oxford, Princeton University Press.

Shimizu, E. (1992). Time-space mapping based on topological transformation of physical map. W.C.T.R. "Sixième conférence mondiale sur la recherche dans les transports", Lyon.

Smith, D. and M. Timberlake (2002). Hierarchies of dominance among world cities: a network approach. Global networks, linked cities. S. Sassen. London, Routledge: 117141.

Spiekermann, K. and M. Wegener (1994). "The Shrinking continent: new time-space maps of Europe." Environment and planning B.: planning and design 21: 653-673.

Taylor, P. (2004). World city network, a global urban analysis. Oxon, Routledge.

Tobler, W. R. (1997). Visualizing the impact of transportation on spatial relations. Western Regional Science Association meeting, Hawaii. 
Tobler, W. R. (1999). The World is Shriveling as it Shrinks. San Diego, ESRI User Conference.

Viard, J. (2008). Eloge de la mobilité, essai sur le capital temps libre et la valeur travail. Paris, Editions de l'Aube. 